\title{
VENLAFAKSINN VE PAROKSETİN KULLANIMINA BAĞLI, ORGAZM OLMAKSIZIN IDRAR SONRASINDA ORTAYA ÇIKAN SPONTAN EJAKÜLASYONLAR: BİR OLGU SUNUMU
}

\author{
Spontaneous Ejaculation without Orgasm after Micturition Induced by \\ Venlafaxine and Paroxetine: A Case Report
}

\author{
Mehmet Hamdi ÖRÜM¹, Mahmut Zabit KARA ${ }^{2}$, Oğuzhan Bekir EĞİLMEZ1

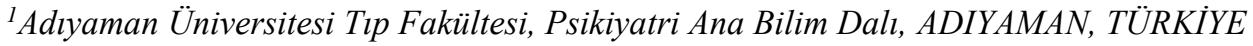 \\ ${ }^{2}$ Adlyaman Üniversitesi EAH, Çocuk ve Ergen Ruh Sağlı̆̆ ve Hastalıklarl, ADIYAMAN, TÜRKIYE
}

\begin{abstract}
Miksiyonu takiben ortaya çıkan spontan ejakülasyon, antidepresanların nadir görülen bir yan etkisidir. Serotonin noradrenalin geri alım inhibitörleri (SNGI) ve seçici serotonin geri alım inhibitörleri (SSGI)'nin spontan ejakülasyona neden olduğu bildirilmiştir. Venlafaksin bir SNGİ, paroksetin ise bir SSGI'dir. Mide bulantısı, kabızlık, iştah ve uyku değişiklikleri venlafaksin ve paroksetin kullanımı ile ilgili bazı yan etkilerdir. Biz bu olgu sunumunda, venlafaksin başlanan erkek hastada ortaya çıkan spontan ejakülasyonu ele aldık. Spontan ejakülasyonlar venlafaksin kesilip, paroksetine geçildikten sonra devam etti. Sadece sertralin kullanılması sırasında yan etki bildirilmedi. S1k görülmeyen bu yan etki, venlafaksin ve paroksetin alan hastalarda sorgulanmalıdır. Aksi takdirde bu yan etki hastalarda utanma ve uyumsuzluğa neden olabilmektedir.
\end{abstract}

Anahtar Kelimeler: Cinsel işlev bozukluğu, ejakülasyon, paroksetin, sertraline, venlafaksin
Spontaneous ejaculation after micturition is a rare side effect of antidepressants. Serotonin noradrenaline reuptake inhibitors (SNRIs) and selective serotonin reuptake inhibitors (SSRIs) are reported to cause spontaneous ejaculation. Venlafaxine is a SNRI, paroxetine is a SSRI. Nausea, constipation, appetite and sleep changes are some side effects associated with the use of venlafaxine and paroxetine. We report the case of a man who had spontaneous ejaculations after using venlafaxine. Spontaneous ejaculations continued after the switching to paroxetine. The side effect ceased after discontinuation of paroxetine and did not appear with sertraline. This unusual side effect should be questioned in patients who receive venlafaxine and paroxetine, as it may cause embarrassment and noncompliance.

Keywords: Sexual dysfunction, ejaculation, paroxetine, sertraline, venlafaxine 


\section{GİİS}

Antidepresan ilaçların cinsel yan etkileri yaygın olarak görülmektedir. Antidepresan alan hastalar cinsel işlevin istek, uyarılma ve orgazm aşamalarını etkileyebilen cinsel işlev bozuklukları bildirmektedir. Gecikmiş ereksiyon ve anorgasmi en sık görülen cinsel yan etkilerdir, ancak mirtazapin, trazodon ve bupropion kullanımına bağlı spontan orgazmlar da literatürde bulunmaktadır (1-4). Venlafaksin bir serotonin ve noradrenalin geri alım inhibitörü (SNGI)'dir (5). Paroksetin de seçici serotonin geri alım inhibitörüdür (SSGI)'dir (6). Kabızlık, baş dönmesi, uyuşukluk, bulantı, iştahsızlık, kserostomi gibi yan etkiler her iki ilacın kullanımında da sık gözlenmektedir $(5,6)$. Biz bu olgu sunumunda venlafaksin ve paroksetin kullanımına bağlı, miksiyon sonrasında orgazm olmaksızın ortaya çıkan spontan ejakülasyonları ele aldık.

\section{OLGU}

28 yaşında erkek, bekâr, Adıyaman'da yaşayan, lise mezunu hasta, 2 yıldır "Ruhsal Bozuklukların Tanısal ve Sayımsal El Kitabı-5" (DSM-5)'e göre major depresif bozukluk tanısıyla polikliniğimizde takip edilmekte ve geçmişte kullandığı ilaçların mirtazapin, ketiapin olduğu öğrenildi. Hastaya sıkıntı, isteksizlik, uykusuzluk, iştahsızlık gibi şikâyetlerle venlafaksin $37.5 \mathrm{mg} /$ gün başlandı ve kademeli olarak $150 \mathrm{mg} /$ gün dozuna çıkarıldı. İki ay sonraki muayenesinde kısmi iyileşme görülen hastanın ilaç dozu $225 \mathrm{mg} /$ gün dozuna çıkarıldı. Bir ay sonraki kontrolünde şikâyetlerinde belirgin gerileme olduğu ifade edildi. Ancak miksiyonu takiben iç çamaşırında ejakülat gördüğünü, bunun $150 \mathrm{mg} /$ gün dozunda başladığını, geçer diye daha önce belirtmek ihtiyacı hissetmediğini ifade etti. İlaç dozunun kademeli olarak azaltılması ve yan etkinin görülmediği tedavi edici ve semptom giderici bir dozda kalınması planlandı. Ancak $75 \mathrm{mg} /$ gün dozunda bile bu şikâyetinin azalmakla beraber devam etmesi üzerine 37.5 $\mathrm{mg} /$ gün dozunda paroksetin $10 \mathrm{mg} /$ gün eklendi ve 15 gün sonra venlafaksin kesildi. Paroksetin dozu 15 gün sonra 20 mg/gün'e çıkarıldı, spontan ejakülasyon devam etti. Bir süre daha bu dozda devam edilmesi planlandı ancak 3 ay boyunca $20 \mathrm{mg} /$ gün dozda paroksetin ile kısmi semptomatik gerileme görülen hastadaki spontan ejakülasyon yan etkisi venlafaksine göre daha az sayı ve miktarda olmakla birlikte devam etti. Paroksetin kesilip, sertralin $25 \mathrm{mg} / \mathrm{gün}$ başlandı, kademeli olarak $100 \mathrm{mg} /$ gün'e çıkarıldı. Yan etki bildirilmedi. Psikiyatrik semptomları önemli oranda azaldı. Bu olgu sunumunun yayınlanması için hastadan gerekli yazılı onam alındı.

\section{TARTIŞMA}

Venlafaksin bir SNGİ, paroksetin bir SSGI'dir $(5,6)$. Atomoksetin, bupropion, duloksetin, reboksetin, nefazodon, milnasipran, zotepin, metilfenidat ve bizim olgumuzda olduğu gibi venlafaksin gibi noradrenerjik özellikleri olan ilaçlara bağlı spontan ejakülasyon yan etkisi bildirilmiştir (1,5-7). Venlafaksin dual bir SNGI'dir (5). Daha önceden $75 \mathrm{mg}$ dozunda spontan ejakülasyon yan etkisi bildirilen bir olguda, bu durum serotoninerjik mekanizmaya atfedilmiştir (5). Bizim hastamızda, yan etki ilk olarak $150 \mathrm{mg} /$ gün dozunda hasta tarafından farkedilmiş, fakat doz 75 mg/gün'e düşürüldüğünde de bu yan etki devam etmiş̧ir. Bu durumun hastanın 75 mg/gün'e ilk doz artırımında var olduğu halde yan etkiyi farketmemesine bağlı olabileceği düşünülmüştür. Bizim hastamızda hem serotonin hem de noradrenalinin yan etkinin ortaya çıkmasında etkili olabileceği düşünülmüştür. Essitalopram, sitalopram ve paroksetin kullanımına bağlı spontan ejakülasyon olguları bildirilmiştir $(5,6)$. Spontan ejakülasyonun altında yatan mekanizma tam olarak açıklanamamışıtır. Cinsel uyarılma olmaksızın spontan ejakülasyonlar, çoğunlukla miksiyon veya defekasyondan sonra ortaya çıkmaktadır. Sempatik sistem ejakülasyon latansını düzenlemektedir. Spontan 
ejakülasyon da ejakülatuvar latansın azalması ile ortaya çıkabilir. Preoptik nükleuslar, anterior talamik nükleus ve serotonin (5-Hidroksitriptamin=5HT), dopamin, oksitosin, $\gamma$-aminobütirik asit (GABA), adrenalin, asetilkolin ve nitrik oksit dâhil birçok nörotransmitter, ejakülasyonun düzenlenmesinde rol oynar. 5HT'nin ejakülasyonda birincil rolü vardır. SSGI'lere bağlı cinsel disfonksiyonlar 5HT-1 ve 2'ye atfedilmektedir. 5HT-1A'nin uyarıcı etkileri olduğu bilinmektedir. Somatodendritik 5HT-1A stimülasyonu ejakülatuvar latans süresini kısaltır, tersine postsinaptik 5HT-2C stimülasyonu ejakülasyon inhibisyonuna neden olur. Noradrenalin ise spinal merkezlere seminal emisyona aracilık eder (8).

$\mathrm{Bu}$ olgu sunumu spontan ejakülasyon gelişmesi nedeniyle venlafaksinin kesilip, paroksetin başlanmasını takiben, aynı yan etkinin daha az miktar ve sıklıkta olmakla birlikte devam ettiğini ve sertralin kullanımı ile yan etkinin ortadan kalktığını gösteren ilk çalışmadır. Bizim olgumuzda venlafaksin kullanımına bağlı yan etki daha çok noradrenerjik mekanizmalara atfedilirken, paroksetin kullanımına bağlı yan etki daha çok serotonerjik mekanizmalara atfedilmiştir. Her iki reseptör sistemi ile ilgili yan etki ortaya çıkması bu çalışmayı diğer bildirimlerden ayırmaktadır. Ayrıca bu çalışma literatür taramalarımıza göre, Pae ve ark.'nın çalışmalarından sonraki ilk paroksetin-spontan ejakülasyon ilişkili çalışmadır (6). Hem paroksetin hem de sertralin birer SSGí olmasına karşılık sertralin kullanımı ile yan etki görülmemesi bu konunun üzerinde daha kapsamlı çalışmalar yapılması gerektiğini göstermektedir.

Sonuç olarak, cinsel işlev bozukluğu, antidepresanların ortak bir yan etkisidir ve hastanın cinsel hayatı, ilişki kalitesi ve yaşam kalitesi üzerinde önemli bir etkisi olabilir. Bu yan etkiler, antidepresan tedaviye uyumsuzluğa neden olabilir. Hastalar, psikiyatrik görüşme sırasında cinsel yan etkilerini utandıkları için gizleme eğilimindedir. Ruh sağlığı profesyonellerinin bu ilaçların cinsel yan etkilerine karşılık dikkatli olması önerilmektedir.

Teşekkür: $\mathrm{Bu}$ çalışmayı meslektaşlarımızla paylaşmamız için onay veren hastaya teşekkür ederiz. $\mathrm{Bu}$ olgu sunumundaki verilerden yol çıkılarak hastanın kimliği hakkında yorum yapmak imkânsızdır.

Finans ve Çıkar Çatışması: Yazarlar finansal destek veya çıkar çatışması bildirmemiştir.

\section{KAYNAKLAR}

1. Orum MH, Egilmez OB, Kalenderoglu A. Bupropion extended-release-induced spontaneous orgasms. Dusunen Adam The Journal of Psychiatry and Neurological Sciences. 2018;31:107-9.

2. Egilmez $\mathrm{OB}$, Orum $\mathrm{MH}$. Intercourse type of situational anejaculation or inability to ejaculate intra-vaginally: three case reports from a conservative Islamic community. Psychiatry Clin Psychopharmacol. 2018. Doi: 10.1080/24750573.2018.1468618

3. Orum MH, Egilmez OB. Succesfully treatment of intercourse anejaculation with psychosexual counselling: A very rare case of situational anejaculation specific to penetrative sex with the wife. Rev Int Androl. 2018. Doi: 10.1016/j.androl.2018.09.001

4. Egilmez OB, Orum MH. Duloxetine use can result in retrograde ejaculation. Dusunen Adam The Journal of Psychiatry and Neurological Sciences. 2018;31:324-5.

5. Camkurt MA. Spontaneous ejaculation; caused by venlafaxine, reverted by mirtazapine. Eur Res J. 2015;1(3):157-9. 
6. Pae CU, Kim TS, Lee KU, Kim JJ, Lee CU, Lee SJ et al. Paroxetine-associated spontaneous sexual stimulation. Int Clin Psychopharmacol. 2005;20(6):339-41.

7. Camkurt MA, Yilmaz MF, Gunes S. Spontaneous ejaculation induced by duloxetine. Anatolian Journal of Psychiatry. 2016;17(3):14-6.

8. Sivrioglu EY, Topaloglu VC, Sarandol A, Akkaya C, Eker SS, Kirli S. Reboxetine induced erectile dysfunction and spontaneous ejaculation during defecation and micturition. Prog Neuro-Psycho-pharmacology Biol Psychiatry. 2007;31(2):548-50. 